\title{
Immunisation-related Knowledge, Attitudes and Promotive Practices among Mothers in an Urban Primary Health Care Centre in South-East Nigeria: a Call for Improved Clinic-based Education
}

\author{
Okedo-Alex IN ${ }^{1,2 *}$,Akamike IC ${ }^{1,2}$, Adeke $\mathrm{AS}^{2}$, Uneke CJ $^{1}$ \\ ${ }^{1}$ African Institute for Health Policy and Health Systems, Ebonyi State University, Abakaliki \\ ${ }^{2}$ Department of Community Medicine, Alex Ekwueme University Federal Teaching Hospital \\ Abakaliki, Ebonyi State, Nigeria \\ Corresponding author: Dr. Okedo-Alex, Ijeoma, ijeomaninadr@gmail.com, +234 \\ 8064927291
}

Address: African Institute for Health Policy and Health Systems, Ebonyi State University, Abakaliki

\begin{abstract}
Background: Nigeria is among the five countries accounting for half of the world's unimmunised children. Maternal knowledge and attitude play key roles in uptake and timeliness of routine childhood vaccination. This study assessed immunisation-related knowledge, attitudes and promotive practices among mothers in Abakaliki Ebonyi State Nigeria.
\end{abstract}

Methods: This was a cross-sectional study among 117 mothers with children aged 0-23 months attending a Primary Health Care Centre in Abakaliki, Ebonyi State. Data were collected using an intervieweradministered questionnaire and analysed using SPSS version 20 with a $p$ value of $\leq 0.05$ considered statistically significant.

Results: Over half (55.6\%) of the respondents were aged 26-35years while 47\% had secondary school education. Majority (91.5\%) had previously vaccinated their children, but only $31.7 \%$ knew the dosing of polio vaccine. Less than half (42\%) of the mothers had adequate knowledge about routes of vaccine administration. About half (49.7\%) had adequate knowledge about the children's next vaccination appointments. Most (94\%) considered immunisation important in preventing childhood diseases with up to 95\% of them willing to bring their children for immunisation. Only $57.3 \%$ were satisfied with the adequacy of immunisation-related information received from the clinic. Majority (81.2\%) were timely in accessing immunisation for their babies. Educational status $(P=0.035)$ and child's age $(P=0.008)$ were associated with knowledge and practice of immunisation respectively.

Conclusion: Mothers in this study had good immunisation-related practices and positive attitude towards immunisation. Although majority had good knowledge, some knowledge gaps were identified. We recommend improved maternal education and content of clinic-based education on immunisation.

Keywords: Immunisation knowledge, mothers' attitude, practices 


\section{Introduction}

Immunisation is a proven cost-effective health investment for controlling lifethreatening infections and is estimated to avert 2-3 million deaths annually. It prevents about a third of under-five mortality and can serve as a bridge to other life-saving care services for mothers and children. $^{1,2}$ Nonetheless, it is a huge concern that globally, more than 19 million children miss routine immunisation, 13 million out of which have never been inoculated in the past. ${ }^{2}$ This reflects in under-five mortality as 1.4 million deaths in this age group are attributable to vaccine-preventable diseases. ${ }^{2,3}$ Nigeria is one of the 5 countries accounting for half of the world's unimmunised children. ${ }^{4}$

Lack of awareness and mistrust towards immunisation are the most cited reasons for poor uptake and non-completion of vaccination in Nigeria. Studies have shown that mothers do not have adequate knowledge on immunisation despite their good attitude towards immunisation. _- ${ }^{-612}$ Only a few studies reported negative attitude towards immunisation among mothers. ${ }^{6}$ A range of practices that promote child immunisation have been explored by previous studies. These include taking the child for immunisation, timeliness, and completion of immunisation. These studies found that although mothers brought their babies for immunisation, non-completion, and poor timeliness hampered adequate uptake of vaccination services. $^{7,1217}$ Both child and maternalrelated factors have also been found to influence uptake, and completion of childhood immunisation. ${ }^{7,1316,1820}$

Ebonyi State has the lowest uptake of BCG and hepatitis $\mathrm{B}$ vaccine at birth in southeastern Nigeria. ${ }^{5,21}$ Although vaccination with the third dose of pentavalent vaccine in the State slightly improved from $80.1 \%$ in 2013 to $82.4 \%$ in $2018,,^{21,22}$ it remains below the $90 \%$ coverage target and the reasons for this are poorly understood. Given the important role of mothers in immunisation uptake, the authors hope that findings from this study will add to the existing body of knowledge as well as prove useful in designing context-specific clinic-based interventions to promote immunization related maternal knowledge, attitudes and practices in Ebonyi State and other similar settings. The objective of this study was to assess immunisation-related knowledge, attitudes and promotive practices among mothers in an urban Primary Health Care (PHC) centre in Abakiliki, south east Nigeria.

\section{Study setting}

\section{Methods}

The study was conducted in Abakaliki, Abakaliki Local Government Area (LGA), Ebonyi State. Abakaliki, is the capital city of Ebonyi State located in south-east Nigeria. According to the 2006 population and housing Census, the population of Ebonyi State is approximately 2,176,947 with an area of 5,935 square kilometres. ${ }^{23}$ The State lies between latitudes $5^{\circ} 40^{\prime}$ and $6^{\circ} 54^{\prime} \mathrm{N}$ and longitudes $7^{\circ} 30^{\prime}$ and $8^{\circ} 30^{\prime} \mathrm{E} .{ }^{24}$ It shares boundaries with Benue State to the north, Cross River State to the east, Enugu State to the west, and Abia State to the south. There are three senatorial zones and thirteen LGAs in the State. Infants constitute $4 \%$, the under-five children $20 \%$ and women of child bearing age $22 \%$ of the population. ${ }^{24}$ About $75 \%$ of the population are involved in subsistence agriculture, and the crops grown in the State include yam, rice, cassava and maize. The area is also endowed with various minerals such as limestone, copper, coal, zinc, lignite, lead and salt

Abakaliki LGA has two tertiary health facilities namely the National Obstetric Fistula Centre and Alex Ekwueme Federal University Teaching Hospital. There is 
also a general hospital, $32 \mathrm{PHC}$ centres and 11 private health facilities offering immunisation services in the LGA. The PHC in which the study was conducted offers services such as immunisation, antenatal care and management of uncomplicated pregnancies and childbirths, family planning, treatment of common illnesses and referral services. Child immunisation sessions are conducted once a week with an average of 35 mother/caregiver-child pairs per session.

\section{Study design and population}

This was a cross-sectional study. The study population consisted of mothers and caregivers of children 0-23 months of age who were residents in this area. All mothers who brought their children for immunisation at the $\mathrm{PHC}$ centre over a one month period were consecutively recruited into the study. Those who did not give informed consent and those who were staff at the PHC were excluded.

\section{Sample size determination and sampling technique}

The sample size was calculated using the sample size formula for a single proportion: ${ }^{25} \mathrm{n}=\mathrm{Z}^{2} \mathrm{p}(1-\mathrm{p}) / \mathrm{d}^{2}$, where $\mathrm{n}=$ minimum sample size, $\mathrm{p}=$ proportion of mothers who correctly identified at least two vaccine-preventable diseases in a similar study in Enugu State $(93.4 \%)^{17}, d=$ the absolute precision of the study which is $0.05, Z=$ Area under normal curve corresponding to $95 \%$ confidence interval (1.96). Using this formula, a minimum sample size of 95 was calculated. This was rounded up to 106 after adjusting for a nonresponse rate of $10 \%{ }^{25}$ A total of 117 respondents were consecutively recruited in the PHC over a one month period. All eligible participants were included. Each participant was only interviewed once and by the $4^{\text {th }}$ week, only first-time attendees to the immunisation clinic and those who missed their appointment (previously not surveyed) were recruited.

\section{Data collection}

This study was conducted among mothers with children aged 0-23 months attending the immunisation clinic of an urban PHC centre in Abakaliki. Data was collected using an interviewer-administered structured questionnaire adapted from similar studies. ${ }^{9,26,27}$ The questionnaire was divided into three sections: sociodemographic information, knowledge assessment, attitude assessment and promotive practices assessment. Knowledge of immunisation was measured by respondents' self-assessment of the adequacy of their knowledge of immunisation, dosing of polio vaccine, diseases prevented by immunisation, routes of vaccine administration, and next vaccination appointment using questions on a 5-point Likert scale. Attitude towards childhood immunisation was determined by questions on importance of immunisation in children, willingness to bring the child for immunisation, willingness to advise other mothers on immunisation, perception of adequacy of vaccines on the immunisation schedule for protecting the child from diseases, and adequacy of clinic health education on details of child immunisation. On practice, timeliness of immunisation visits, frequency of checking child's immunisation card, and practice of peer advice to other mothers to promote immunisation uptake were assessed. The questionnaire was pre-tested among mothers and caregivers of children 0-23 months of age accessing immunisation services in another PHC in Abakaliki following which the required corrections were identified and effected 


\section{Data management and analysis}

The independent variables were the sociodemographic characteristics of the participants and their children (maternal age, marital status, educational status, child's age and birth order) and previous immunisation status of the child. The dependent variables were the knowledge, attitude and promotive practice towards childhood immunisation.

Knowledge of childhood immunisation was assessed using 5 questions on a 5 point Likert scale. Four of the questions assessed self-rated adequacy of knowledge on dosing of polio vaccine, diseases preventable by immunisation and routes of vaccine administration on a scale ranging from very adequate to grossly inadequate. The options to these Likert scale questions were scored as: grossly inadequate $=1$. Inadequate $=2$, fairly adequate $=3$, adequate $=4$ and very adequate $=5$. Two questions assessed the degree of agreement with statements on the prevention of childhood diseases by immunisation and knowledge of the child's next vaccination appointment. The options were scored as: 1 point $=$ strongly disagree, 2 points $=$ disagree, 3 points $=$ undecided, 4 points $=$ agree and 5 points $=$ strongly agree Attitude towards immunisation was explored using 5-point Likert scale questions. Two questions were on willingness to bring the child for immunisation and advise other mothers on the same. The options to the questions were scored as $1=$ strongly unwilling, $2=$ unwilling, $3=$ neutral, 4=willing and $5=$ strongly willing. One of the 5 questions assessed the perceived importance of immunisation using a 5-point Likert scale question ranked as follows: 1=grossly unimportant, $2=$ unimportant, $3=$ undecided, $4=$ important, 5=very important. One question assessed the attitude (agreement on a statement) towards the adequacy of the vaccines on the immunisation schedule for the child's protection and the options were scored as $1=$ strongly disagree, $2=$ disagree, $3=$ undecided, $4=$ agree and $5=$ strongly agree.

Promotive practices towards childhood immunisation were assessed using three questions on timeliness of immunisation, frequency of checking the child's immunisation card and advising other mothers on vaccinating their children. Timeliness was determined using one 5point Likert scale question ranked as $1=$ very untimely, $2=$ untimely, $3=$ fairly timely, $4=$ timely and $5=$ very timely. The other two questions were scored as follows: $1=$ very rarely, $2=$ rarely, $3=$ sometimes, $4=$ often and $5=$ very often.

To assess the knowledge, attitude and promotive practices among the mothers, the Mean Neutral Rating (MNR) of the Likert scale responses was done using the methods developed at McMaster University Canada by Johnson and Lavis.28 Knowledge was classified as satisfactory at mean values between 3.00 and 5.00 while values less than 3.00 were categorized as unsatisfactory. Attitude and practice were classified as positive and good respectively at mean values between 3.00 and 5.00 while values less than 3.00 were categorized as negative attitude and poor practice respectively.26,29,30

Data entry and analysis were done using SPSS version 20. Frequencies and proportions were calculated for categorical variables. The categorical variables for which proportions were calculated were maternal age, marital status, educational status, child's age and birth order and previous immunisation status of the child, all Likert-scale knowledge, attitude and practice parameters assessed (described above), graded knowledge, attitude and practice of immunisation.

Means and standard deviations were also calculated for all Likert-scale knowledge, 
attitude and practice parameters assessed (described above). The median and interquartile range of responses was also presented. The Chi-square statistic was used to determine the relationship between the independent variables and the dependent variables at $5 \%$ level of significance.

\section{Ethical consideration}

Ethical clearance for this study was obtained from Research and Ethics Committee of Ebonyi State University, Abakaliki. Only those respondents who gave their informed consent by signing the informed consent form participated in the study. The questionnaire did not include self-identifying characteristics and participation was voluntary.

\section{Results}

A total of 117 respondents participated in the study. Respondents were mostly aged $26-35$ years $(55.6 \%)$, married $(94.9 \%)$ and self-employed (60.7\%). About half (47\%) had secondary school education and majority had previously immunised their children $(91.5 \%)$. Fifty-six percent of the children were aged 0-3 months. (Table 1)

The overall mean knowledge score was $3.21 \pm 1.02$ with values ranging from 2.51 to 3.85. Most of the mothers $(83.8 \%$, mean $3.85 \pm 1.18)$ knew that immunisation prevents childhood illnesses while only $31.7 \%$ (mean $2.51 \pm 1.44$ ) had adequate knowledge of the dosing of the polio vaccine. Only $40.2 \%$ of the respondents (mean $3.03 \pm 1.53$ ) had adequate knowledge of the diseases prevented by childhood immunisation while only $41.9 \%$ (mean $3.17 \pm 1.71$ ) had adequate knowledge of the routes of vaccine administration. Almost half (49.6\%) of respondents (mean $3.46 \pm 1.66$ ) knew the date for their child's next vaccination appointment. Fifty-eight percent of the respondents had satisfactory knowledge on immunisation. [Table 2].

The overall mean attitude score was $4.01 \pm 0.55$ and most of respondents $(94 \%$, mean $4.45 \pm 0.74)$ considered immunisation to be important in children. Up to $95.7 \%$ (mean $4.32 \pm 0.63$ ) were willing to bring their children for immunisation and to advise other mothers to do the same $(82.1 \%$, mean $3.87 \pm 0.89)$. A larger proportion of the mothers $(72.6 \%$, mean $3.89 \pm 0.93)$ perceived the vaccines on the immunisation schedule adequate to protect the child and also considered clinic information on immunisation adequate

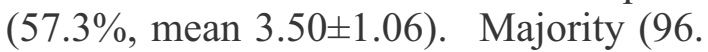
$6 \%$ ) had a positive attitude towards immunisation [Table 3]

The overall mean practice of immunisation was $3.90 \pm 0.85$. Majority of the mothers $(88.8 \%$, mean $4.42 \pm 1.05)$ were timely in accessing immunisation for their babies. Almost three-fifths (58.9\%) of the respondents advised other mothers to practice immunisation while $68.2 \%$ often checked for immunisation-related information on the child's immunisation card. Only $12.1 \%$ had poor practice towards child's immunisation [Table 4]. There was a statistically significant association between maternal educational status and knowledge of immunisation $(P=0.016)$. Mothers with secondary and tertiary education had more knowledge of immunisation than those with at most a primary school education. There was no statistically significant relationship between knowledge and maternal age group, marital status, employment status, child's age and birth order [Table 5].

There was a statistically significant association between maternal knowledge on immunisation and attitude towards child immunisation $(P=0.029)$ but there was no statistically significant relationship between attitude and maternal age group, marital status, employment status, child's age and birth order [Table 6]. 
There was a statistically significant association between practice of child immunisation and child's age $(P=0.008)$. A higher proportion of mothers whose children were more than 8 months old had good immunisation practices. There was no statistically significant relationship between practice of child immunisation and maternal age group, marital status, employment status and child's birth order [Table 7].

Table 1: Socio-demographic characteristics of the mothers and their children

\begin{tabular}{|c|c|c|}
\hline Variables & Frequencies $n=117$ & Percent $(\%)$ \\
\hline \multicolumn{3}{|l|}{ Age group (years) } \\
\hline$<15$ & 1 & 0.9 \\
\hline $16-25$ & 41 & 35.0 \\
\hline $26-35$ & 65 & 55.6 \\
\hline $36-45$ & 10 & 8.5 \\
\hline \multicolumn{3}{|l|}{ Occupation } \\
\hline Unemployed & 31 & 26.5 \\
\hline Self-employed & 71 & 60.7 \\
\hline Civil service & 11 & 9.4 \\
\hline Student & 4 & 3.4 \\
\hline \multicolumn{3}{|l|}{ Marital status } \\
\hline Married & 111 & 94.9 \\
\hline Single & 6 & 5.1 \\
\hline \multicolumn{3}{|c|}{ Highest educational level attained } \\
\hline Tertiary level & 26 & 22.2 \\
\hline Secondary school & 55 & 47.0 \\
\hline Primary school & 32 & 27.4 \\
\hline No formal education & 4 & 3.4 \\
\hline \multicolumn{3}{|l|}{ Age of child (months) } \\
\hline $0-3$ & 66 & 56.4 \\
\hline $4-7$ & 20 & 17.1 \\
\hline $8-12$ & 25 & 21.4 \\
\hline$>12$ & 6 & 5.1 \\
\hline \multicolumn{3}{|l|}{ Child's Birth Order } \\
\hline First & 39 & 33.3 \\
\hline $2^{\text {nd }}-4^{\text {th }}$ & 59 & 50.4 \\
\hline $5^{\text {th }}$ or more & 19 & 16.2 \\
\hline \multicolumn{3}{|l|}{$\begin{array}{l}\text { Previously brought child for } \\
\text { immunisation }\end{array}$} \\
\hline Yes & 107 & 91.5 \\
\hline No & 10 & 8.5 \\
\hline
\end{tabular}


Table 2: Knowledge about immunisation among mothers

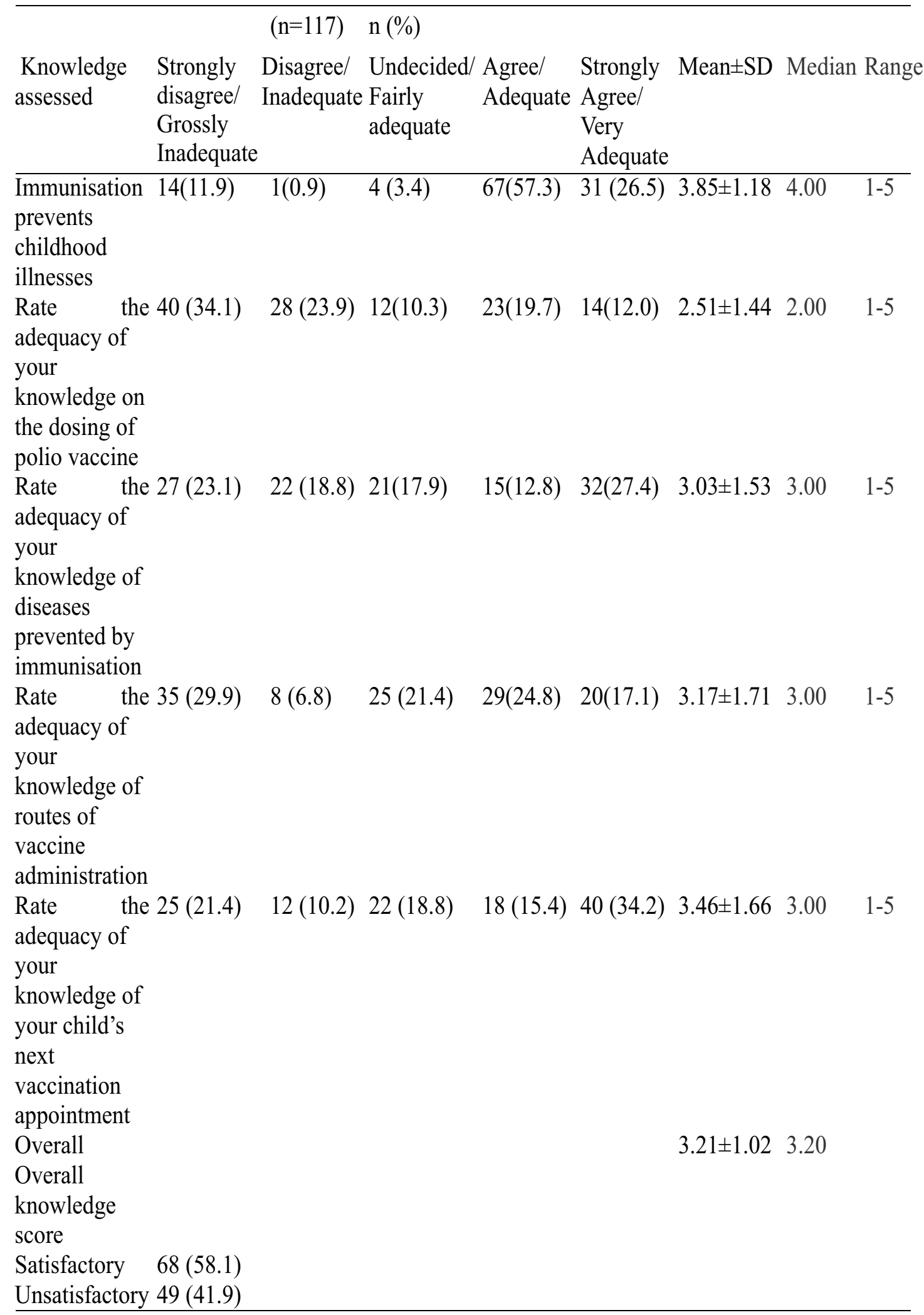


Table 3: Attitude towards immunisation among mothers

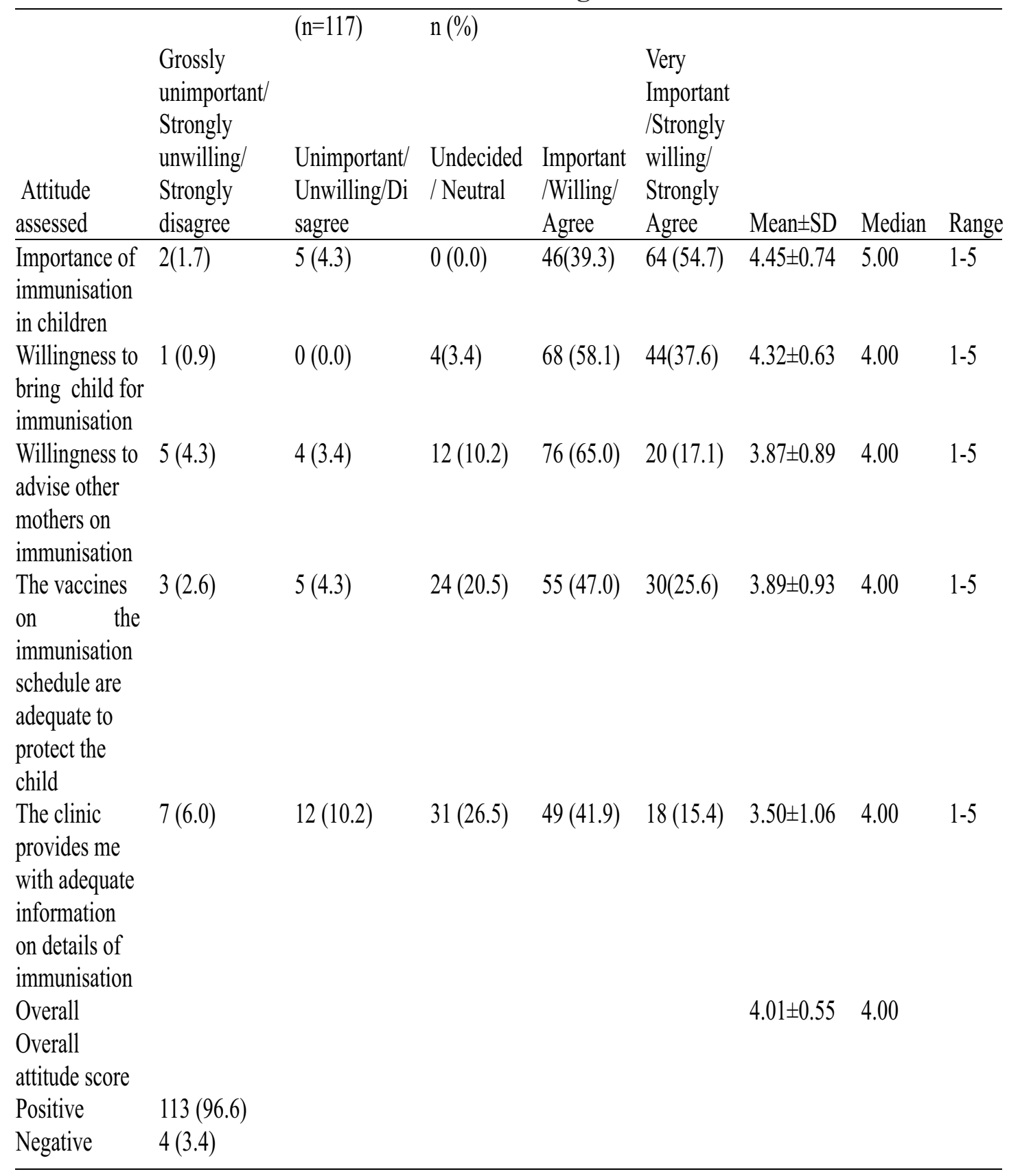


Table 4: Practice towards immunisation among mothers

\begin{tabular}{|c|c|c|c|c|c|c|c|c|}
\hline \multirow[b]{2}{*}{ Practice assessed } & \multirow{2}{*}{$\begin{array}{l}\text { Very } \\
\text { untimely } \\
\text { /Very } \\
\text { Rarely }\end{array}$} & \multirow{2}{*}{$\begin{array}{l}(\mathrm{n}=107) \\
\text { Untimely } \\
\text { /Rarely }\end{array}$} & \multicolumn{6}{|l|}{$\mathrm{n}(\%)$} \\
\hline & & & $\begin{array}{l}\text { Fairly } \\
\text { timely/ } \\
\text { Sometimes }\end{array}$ & $\begin{array}{l}\text { Timely/ } \\
\text { Often }\end{array}$ & $\begin{array}{l}\text { Very } \\
\text { timely/Very } \\
\text { Often }\end{array}$ & Mean \pm SD & Median & Range \\
\hline $\begin{array}{l}\text { Timeliness of } \\
\text { immunisation }\end{array}$ & $5(4.7)$ & $4(3.7)$ & $3(2.8)$ & $24(22.4)$ & $71(66.4)$ & $4.42 \pm 1.05$ & 5.00 & $1-5$ \\
\hline $\begin{array}{l}\text { I advise other } \\
\text { mothers to bring } \\
\text { their children for } \\
\text { immunisation }\end{array}$ & $8(7.5)$ & $7(6.5)$ & $29(27.1)$ & $44(41.1)$ & $19(17.8)$ & $3.55 \pm 1.09$ & 4.00 & $1-5$ \\
\hline $\begin{array}{l}\text { Frequency of } \\
\text { checking child's } \\
\text { immunisation } \\
\text { card }\end{array}$ & $8(7.5)$ & $8(7.5)$ & $18(16.8)$ & $43(40.2)$ & $30(28.0)$ & $3.74 \pm 1.17$ & 4.00 & $1-5$ \\
\hline Overall & & & & & & $3.90 \pm 0.85$ & 3.25 & \\
\hline $\begin{array}{l}\text { Overall practice } \\
\text { score }\end{array}$ & & & & & & & & \\
\hline Good & $94(87.9)$ & & & & & & & \\
\hline Poor & $13(12.1)$ & & & & & & & \\
\hline
\end{tabular}


Table 5: Factors associated with knowledge on childhood immunisation among mothers

\begin{tabular}{|c|c|c|c|c|}
\hline Variable & $\begin{array}{l}\text { Knowledge } \\
\text { Unsatisfactory } \\
(\%)\end{array}$ & $\begin{array}{l}\text { Satisfactory } \\
(\%)\end{array}$ & $\begin{array}{l}\text { Total } \\
(\mathrm{N}=117)\end{array}$ & $\mathrm{X}^{2}(P$--value $)$ \\
\hline \multicolumn{5}{|l|}{ Age groups (years) } \\
\hline$\leq 25$ & $20(47.6)$ & $22(52.4)$ & 42 & $0.886(0.346)$ \\
\hline$\geq 26$ & $29(38.7)$ & $46(61.3)$ & 75 & \\
\hline \multicolumn{5}{|l|}{ Marital status } \\
\hline Single & $3(50.0)$ & $3(50.0)$ & 6 & FT (0.694) \\
\hline Married & $46(41.4)$ & $65(58.6)$ & 111 & \\
\hline \multicolumn{5}{|l|}{ Employment status } \\
\hline Unemployed & $12(34.3)$ & $23(65.7)$ & 35 & $1.183(0.277)$ \\
\hline Employed & $37(45.1)$ & $45(54.9)$ & 82 & \\
\hline \multicolumn{5}{|l|}{ Highest educational level } \\
\hline Primary school and less & $21(58.3)$ & $15(41.7)$ & 36 & $5.783(0.016)^{*}$ \\
\hline $\begin{array}{l}\text { Secondary school and } \\
\text { more }\end{array}$ & $28(34.6)$ & $53(65.4)$ & 81 & \\
\hline \multicolumn{5}{|l|}{ Age of Child (months) } \\
\hline $0-3$ & $29(43.9)$ & $37(56.1)$ & 66 & $0.716(0.699)$ \\
\hline $4-7$ & $9(45.0)$ & $11(55.0)$ & 20 & \\
\hline 8 and above & $11(35.5)$ & $20(64.5)$ & 31 & \\
\hline \multicolumn{5}{|l|}{ Birth Order } \\
\hline First & $17(43.6)$ & $22(56.4)$ & 39 & $0.082(0.960)$ \\
\hline $2^{\text {nd }}-4^{\text {th }}$ & $24(40.7)$ & $35(59.3)$ & 59 & \\
\hline $5^{\text {th }}$ or more & $8(42.1)$ & $11(57.9)$ & 19 & \\
\hline
\end{tabular}

*Statistically significant

FT= Fisher's Exact test 
Table 6: Factors associated with attitude towards childhood immunisation among mothers

\begin{tabular}{|c|c|c|c|c|}
\hline \multirow{2}{*}{ Variable } & \multicolumn{2}{|c|}{ Attitude } & \multirow[b]{2}{*}{$\begin{array}{l}\text { Total } \\
(\mathrm{N}=117)\end{array}$} & \multirow[b]{2}{*}{$\mathrm{X}^{2}(P$--value $)$} \\
\hline & $\begin{array}{l}\text { Negative } \\
(\%)\end{array}$ & $\begin{array}{l}\text { Positive } \\
(\%)\end{array}$ & & \\
\hline \multicolumn{5}{|l|}{ Age groups (years) } \\
\hline$\leq 25$ & $2(4.8)$ & $40(95.2)$ & 42 & \multirow[t]{2}{*}{ FT $(0.617)$} \\
\hline$\geq 26$ & $2(2.7)$ & $73(97.3)$ & 75 & \\
\hline \multicolumn{5}{|l|}{ Marital status } \\
\hline Single & $1(16.7)$ & $5(83.3)$ & 6 & \multirow[t]{2}{*}{ FT $(0.192)$} \\
\hline Married & $3(2.7)$ & $108(97.3)$ & 111 & \\
\hline \multicolumn{5}{|l|}{ Employment status } \\
\hline Unemployed & $2(5.7)$ & $33(94.3)$ & 35 & \multirow[t]{2}{*}{ FT $(0.582)$} \\
\hline Employed & $2(2.4)$ & $80(97.6)$ & 82 & \\
\hline \multicolumn{5}{|l|}{ Highest educational level } \\
\hline Primary school and less & $2(5.6)$ & $34(94.4)$ & 36 & \multirow[t]{3}{*}{ FT $(0.586)$} \\
\hline Secondary school and more & $2(2.5)$ & $79(97.5)$ & 81 & \\
\hline Age of Child (months) & & & & \\
\hline $0-3$ & $2(3)$ & $64(97.0)$ & 66 & \multirow[t]{3}{*}{ FT $(0.191)$} \\
\hline $4-7$ & $2(10.0)$ & $18(90.0)$ & 20 & \\
\hline 8 and above & $0(0.0)$ & $31(100)$ & 31 & \\
\hline \multicolumn{5}{|l|}{ Birth Order } \\
\hline First & $1(2.6)$ & $38(97.4)$ & 39 & \multirow[t]{3}{*}{ FT $(1.00)$} \\
\hline $2^{\text {nd }}-4^{\text {th }}$ & $3(5.1)$ & $56(94.9)$ & 59 & \\
\hline $5^{\text {th }}$ or more & $0(0.0)$ & $19(100.0)$ & 19 & \\
\hline
\end{tabular}

*Statistically significant FT= Fisher's Exact test 
Table 7: Factors associated with practice of childhood immunisation among mothers

\begin{tabular}{|c|c|c|c|c|}
\hline \multirow[t]{2}{*}{ Variable } & \multicolumn{4}{|c|}{ Frequency $(\%)$} \\
\hline & Poor & Good & $\begin{array}{l}\text { Total } \\
(\mathrm{n}=107)\end{array}$ & $\mathrm{X}^{2}(P$ value $)$ \\
\hline \multicolumn{5}{|l|}{ Age groups (years) } \\
\hline$\leq 25$ & $6(15.8)$ & $32(84.2)$ & 38 & \multirow[t]{2}{*}{ FT $(0.537)$} \\
\hline$\geq 26$ & $7(10.1)$ & $62(89.9)$ & 69 & \\
\hline \multicolumn{5}{|l|}{ Marital status } \\
\hline Single & $2(40.0)$ & $3(60.0)$ & 5 & \multirow[t]{3}{*}{ FT $(0.111)$} \\
\hline Married & $11(10.8)$ & $91(89.2)$ & 102 & \\
\hline Employment status & & & & \\
\hline Unemployed & $3(9.4)$ & $29(90.6)$ & 32 & \multirow[t]{2}{*}{$\mathrm{FT}(0.751)$} \\
\hline Employed & $10(13.3)$ & $65(86.7)$ & 75 & \\
\hline \multicolumn{5}{|l|}{ Highest educational level } \\
\hline Primary school and less & $4(12.5)$ & $28(87.5)$ & 32 & \multirow[t]{3}{*}{ FT $(1.000)$} \\
\hline Secondary school and more & $9(12.1)$ & $66(87.9)$ & 75 & \\
\hline Age of Child (months) & & & & \\
\hline $0-3$ & $8(13.8)$ & $50(86.2)$ & 58 & \multirow[t]{4}{*}{$\mathrm{FT}(0.008) *$} \\
\hline $4-7$ & $5(26.3)$ & $14(73.7)$ & 19 & \\
\hline 8 and above & $0(0.0)$ & $30(100)$ & 30 & \\
\hline Birth Order & & & & \\
\hline First & $4(11.4)$ & $31(88.6)$ & 35 & \multirow[t]{3}{*}{ FT $(1.000)$} \\
\hline $2^{\text {nd }}-4^{\text {th }}$ & $7(12.7)$ & $48(87.3)$ & 55 & \\
\hline $5^{\text {th }}$ or more & $2(11.8)$ & $15(88.2)$ & 17 & \\
\hline
\end{tabular}

*Statistically significant $\mathrm{FT}=$ Fisher's Exact test

\section{Discussion}

The findings from this study showed that less than $60 \%$ of the respondents had satisfactory knowledge of immunisation. This finding is higher than knowledge levels from similar studies conducted in northern Nigeria where only $16-32 \%$ of the mothers had good knowledge of immunisation. ${ }^{6,26}$ This could be because our study was conducted in an urban area with majority of the respondents having at least a secondary school education in contrast to those studies conducted in rural areas with less educated mothers. Studies have found that educated mothers have more knowledge of immunisation than the less educated. ${ }^{15,19}$ Higher proportions of good knowledge among mothers has also been reported from similar studies in the south- western States of Nigeria. ${ }^{14,19}$

Similar to our study, majority of mothers in other studies knew that immunisation could prevent major childhood killer diseases. ${ }^{12,17,27}$ However less than half of the respondents had adequate knowledge of the dosing of oral polio vaccine and routes of vaccine administration. In contrast, over $60 \%$ of mothers knew of dosing/schedule of the oral polio vaccine in other studies carried out in Democratic Republic of Congo (DRC) and Nigeria. ${ }^{19,31}$ This draws attention to the need to adequately educate mothers on the scheduling and routes of the different vaccines on the National Immunisation Schedule in order to promote maternal involvement and commitment to completing vaccination appropriate for the child's age. Maternal educational status 
was significantly associated with knowledge of immunisation. Those who were educated were more likely to be knowledgeable on immunisation. This agrees with findings from other similar studies. ${ }^{15,19}$ Access to formal education may likely expose a mother to general information on health and wellbeing (immunisation inclusive) and thus explain the more knowledge on immunisation by the educated mothers. Low maternal education and knowledge on immunisation have also been identified as predictors of default/non-completion of childhood immunisation. ${ }^{16}$.

Almost all of our respondents had a positive attitude towards immunisation. Similarly, findings from other studies show that most of the mothers had a good attitude towards immunisation, ${ }^{7,9}$ In contrast, a study in Kaduna found that $58.4 \%$ of the mothers surveyed had an unfavourable attitude towards immunisation. Lack of access to information on routine immunisation and the consequent poor knowledge were the reasons cited for the unfavourable attitude in this study. ${ }^{6}$ Ninety-four percent of mothers in our study believed that immunisation was important in children and this is consistent with proportions reported from other studies. ${ }^{912,3133}$ A larger proportion of the respondents were convinced that the vaccines on the immunisation schedule were adequate to protect their children's health. Likewise most of the mothers in another study in DRC held a similar opinion on the adequacy of the immunisation schedule. This reflects the confidence that these mothers have on the usefulness of the childhood immunisation despite their suboptimal knowledge of the immunisation schedule. Acceptability and trust in the effectiveness of vaccination is important for adherence to immunisation visits and completion of the immunisation schedule. More than $80 \%$ of the mothers were willing to bring their children for immunisation and to recommend child vaccination to other mothers. Such level of willingness has also been reported in other studies. ${ }^{7,9} \quad$ Although willingness towards child vaccination is not equivalent to timeliness and completion, it can be built upon to reinforce good child vaccination practices towards improving vaccination indices. Slightly over half of the respondents reported that the clinic information provided on immunisation was adequate. Similarly, another study in Egypt found that $61 \%$ of the respondents were satisfied with information on immunisation from the clinic. ${ }^{8}$ In contrast, $96 \%$ of mothers from an Indian study were satisfied with the clinic immunisation information.

Ninety-two percent of the mothers had ever brought a child for immunisation. This is consistent with findings from other studies. ${ }^{7,9,12,17}$ However some studies have documented disparities between the selfreported uptake of child immunisation and the information on actual vaccination from the child's immunisation card. ${ }^{7,9,17,26,31}$ Majority of the mothers affirmed that they were timely in bringing their children for scheduled immunisation. Similarly, high levels of timeliness was reported by most mothers in other studies, though their response could have been influenced by social desirability bias. ${ }^{7,17,27}$ Only $53 \%$ of the mothers checked their child's immunisation card frequently. The child immunisation card should serve as an important source of useful information to the mothers as it contains child-specific clinical information including the date of the next vaccination appointment. It is therefore important to educate mothers on the use of the immunisation card alongside other information on immunisation given to them during health talks in the immunisation clinics. Additionally, only 
fifty four percent of the respondents advised fellow mothers on the need for child vaccination. Maternal peer to peer support and role modelling can prove useful in improving child immunisation uptake and completion. The child's age was associated with practice of childhood immunisation. This could be because mothers with older children may have become more knowledgeable and used to the routine immunisation program hence their good practice.

A limitation of this study is that it could be prone to social desirability bias because unverified self-reports were used to collect the data. However participants were encouraged to give sincere responses and the confidentiality of their responses ensured. Secondly, the study was conducted in just one urban PHC centre and thus its findings may not be generalizable to other PHC centres especially those located in the rural areas and higher levels of care.

\section{Conclusion}

The findings of this study show that a large proportion of the mothers studied had favourable attitude towards, and good practice of childhood immunisation. Although the majority had good knowledge, sub-optimal knowledge on specific areas such as diseases preventable by immunisation, doses and routes of vaccination was identified. Maternal education and age of the child were associated with knowledge and practice respectively. There is need to focus on and encourage the education of the girl-child, and women as this improves their awareness and utilisation of health services such as immunisation. The content of the immunisation clinic health talks given to mothers should be designed to include more specific information on the types, dosing, scheduling and routes of vaccine administration as already contained in the National Primary Health Care immunisation card. Given the educational status of the respondents, information, education and communication (IEC) materials with basic information on immunisation can also be employed. Mothers can also be e $n$ c o u raged a s e e r supporters/immunisation advocates to promote uptake, and completion of immunisation since majority of them were willing to support/advise other mothers on immunisation.

\section{References}

1. United Nations Childrens Fund (UNICEF). Immunization [Internet]. 2018 [cited 2018 Apr 20]. Available $\mathrm{f} \quad \mathrm{r} \quad \mathrm{o} \quad \mathrm{m}$ : https://www.unicef.org/immunizatio

2. WHO, UNICEF, World Bank. State of the worlds vaccines and immunization [Internet]. Geneva; 2009 [cited 2018 May 18]. Available $\mathrm{f} \quad \mathrm{r} \quad \mathrm{o} \quad \mathrm{m}$ : http://www.who.int/immunization/so wvi/en/

3. United Nations. UN News [Internet]. News. 2018 [cited 2018 May 17]. A va i $1 \mathrm{able}$ f r o m : http://news.un.org/en/story/2018/04/1 008162

4. Centers For Disease Control and Prevention. Polio eradication [Internet]. Global health. 2017 [cited 2018 May 17]. Available from: https://www.cdc.gov/polio/

5. National Primary Healthcare Development Agency (NPHCDA). National Immunization Coverage Survey. Abuja; 2017.

6. Taiwo L, Idris S, Abubakar A, Nguku P, Nsubuga P, Gidado S et al. Factors affecting access to information on routine immunization among mothers 
of under 5 children in Kaduna State Nigeria , 2015. Pan Afr Med J. 2017;27(186):18.

7. Odia OJ, Okafor IP, Roberts AA. Knowledge, Attitude and Practice of Childhood Immunization among Mothers of Under-Fives in Kosofe Local Council Development Area, Lagos State. J Community Heal Prim Heal Care. 2015;27(1):5563.

8. El Gammal HA. Maternal satisfaction about childhood immunization in primary health care center, Egypt. Pan Afr Med J. 2014;18:157.

9. Mahalingam S, Soori A, Ram P, Achappa B, Chowta M, Madi D. Knowledge, attitude and perceptions of mothers with children under five years of age about vaccination in Mangalore, India. Asian J Med Sci. 2014;5(4):527.

10. Ojikutu RK. Beliefs, Knowledge and Perception of Parents to Paediatric Vaccination in Lagos State, Nigeria. J Manag Sustain. 2012;2(2):22735.

11. Adisa OP, Akinleye CA, Obafisile CI, Oke OS. Childhood immunization perception and uptake among mothers of under-five children attending immunization clinics in Osogbo, South Western, Nigeria. Res J Heal Sci. 2016;4(3):18694.

12. Abidoye AO, Odeyemi KA. Knowledge, attitude and practice of mothers to childhood Immunization in Kosofe Local Government Area of Lagos State, Nigeria. Int J Basic, Appl Innov Res. 2013;2(4):6672.

13. Kassahun MB, Biks GA, Teferra AS. Level of immunization coverage and associated factors among children aged 1223 months in Lay Armachiho District, North Gondar Zone, Northwest Ethiopia: a community based cross sectional study. BMC Res Notes. 2015;8:239.

14. Adedire EB, Ajayi I, Fawole OI,
Ajumobi O, Kasasa S, Wasswa P, et al. Immunisation coverage and its determinants among children aged 1223 months in Atakumosa-west district , Osun State Nigeria: a cross-sectional study. BMC Public Health. 2016;16:905.

15. Legesse E, Dechasa W. An assessment of child immunization coverage and its determinants in Sinana District, Southeast Ethiopia. BMC Paediatr. 2015;15(31):114.

16. Asfaw AG, Koye DN, Demssie AF, Zeleke EG, Gelaw YA. Determinants of default to fully completion of immunization among children aged 12 to 23 months in South Ethiopia: unmatched case-control study. Pan Afr Med J. 2016;23:100.

17. Tagbo BN, Nwokoye IC, Eze JC, Omotowo IB. Mothers knowledge, perception and practice of childhood immunization in Enugu. Niger J paed. 2012;39(3):906.

18. Lakew Y, Bekele A, Biadgilign S. Factors influencing full immunization coverage among 1223 months of age children in Ethiopia: evidence from the national demographic and health survey in 2011. BMC Public Health [Internet]. 2015;15:728. Available f $\quad r \quad 0 \quad$ m : http://dx.doi.org/10.1186/s12889015-2078-6

19. Fatiregun AA, Etukiren EE. Determinants of uptake of third doses of oral polio and DTP vaccines in the Ibadan North Local Government Area of Nigeria. Int Health. 2014;6:21324.

20. Mohamud AN, Feleke A, Worku W, Kifle M, Sharma HR. Immunization coverage of 1223 months old children and associated factors in Jigjiga District, Somali National Regional State, Ethiopia. BMC Public Health. 2014;14:865.

21. National Population Commission 
(NPC) [Nigeria] and ICF. Nigeria Demographic and Health Survey 2018. Abuja, Nigeria and Rockville, Maryland, USA; 2019.

22. National Population Commission (NPC) [Nigeria] and ICF Macro. Nigeria Demographic and Health Survey 2013. Abuja; 2013.

23. National Population Commission. Population and housing census of the federal republic of Nigeria [Internet]. Abuja; 2006 [cited 2016 Sep 24]. A vail a ble from : http://www.population.gov.ng/indexp $\mathrm{hp} /$ publications

24. Ebonyi State Ministry of Health. Ebonyi State Government Strategic Health Development Plan. Abakaliki,; 2010.

25. Araoye MO. Research Methodology with Statistics for Health and Social Sciences. 1st ed. Ilorin: Nathadex Publishers; 2004. 121122 p.

26. Gidado S, Nguku P, Biya O, Waziri NE, Mohammed A, Nsubuga P. Determinants of routine immunization coverage in Bungudu, Zamfara State, northern Nigeria, May 2010. Pan Afr Med J. 2014;18(Suppl $1): 9$.

27. Vonasek BJ, Bajunirwe F, Jacobson LE, Twesigye L. Do Maternal Knowledge and Attitudes towards Childhood Immunizations in Rural Uganda Correlate with Complete Childhood Vaccination? PLoS One. 2016;11(2):116.
28. Lavis JN, Permanand G, Oxman AD, Lewin S, Fretheim A. SUPPORT Tools for evidence-informed health Policymaking ( STP ) 13: Preparing and using policy briefs to support evidence-informed policymaking. Heal Res Policy Syst. 2009;7(Suppl 1):S13.

29. Uneke CJ, Ezeoha A, Uro-Chukwu HC. Promoting evidence - informed policymaking through capacity research for health researchers and policymakers in Nigeria: A cross sectional study. J Educ Health Promot. 2018;7(28).

30. Odusanya OO, Alufohai EF, Meurice FP, Ahonkhai VI. Determinants of vaccination coverage in rural Nigeria. BMC Public Health. 2008;8:381.

31. Mapatano MA, Kayembe K, Drph LP. Immunisation-related knowledge, attitudes and practices of mothers in Kinshasa, Democratic Republic of the Congo. South African Fam Pract. 2008;50(2):61.

32. Delkhosh M, Negarandeh R, Ghasemi E, Rostami H. Maternal concerns about immunization over 024 month children: a qualitative research. Issues C o m p r P e d i a t r N u r s. 2014;37(4):23549.

33. Dorota Mrozek-Budzyn, Kieltyka A, Mroz Elzbieta. Opinions about Vaccination among Mothers Who Delivered Newborns in two Hospitals in Krakow and Myslenice. Prezegl Epidemiol. 2016;70(3):4718. 